Female Flowers in Conifere.-Quite recently Celakovsky has published a very elaborate criticism (on the structure of the female flowers in Coniferæ, as detailed in Eichler's well-known treatise). To this ("Zur Kritik der Ansichten von der Fruchtschuppe der Abietineen," \&c. Prag, 1882), Eichler 'has replied in a paper read before the Gesellschaft der Nat. Freunde $z$ Berlin, in which he re-states the chief points of his proof and answers seriatim the objections brought against it. Dr. Peters suins these up as follows:-1. In all the vegetative buds of the pine, the two front leaves (Vorblätter) converge forwards towards the bract; it is hence improbable that in the fruit scale they should be turned backwards. Celakovsky, from the fact that in weak buds the former arrangement is somewhat modified, concludes that on the complete falling away of the bud from between the front leaves, these latter are enabled to push themselves backwards and cohere: an opinion not proved. 2. While in the vegetative bud, the leaf immediately following the front leaf falls backwards in abnormal fruit-scales, the portion interpreted as the next leaf falls forwards. To the representation of Celakovsky's, that owing to the fact that the front side being, in the course of development, preferentially assisted, the leaf of the assisted front side first reaches its development, Eichler opposes the statement that in the ordinary buds there is not a trace of such a preferential furtherance. 3. The part that is re. garded as the third leaf of the bud cannot be a leaf, because it has its xylem on the dorsal, and its phloëm on its ventra surface. Celakovsky takes a twist of $180^{\circ}$ for granted. This Eichler denounces as an evasion which would bring all serious scientific discussion to an end. 4. If the fruit-scale were formed by the growing together of two front leaves upon the hinder end of their axis, the latter if it developed further, would come to stand on the front side of the fruit-scale, but de facto it under such conditions stands behind. As Celakovsky however thinks that the middle piece of the front scale is half turned round, and is a leaf on the front side of the bud, to which both front leaves on the front side of the bud have adhered, by which means the axis comes to be posterior : therefore this opinion stands irreconcilably contradicted by his own supposition of the simultaneous pushing back of the front leaves. 5. The simplest explanation of the bud-arrangement, and of the bud itself, is got by supposing that the bract and the fruit-scale form together a single leaf which has produced an axillary bud. Here Eichler considers himsel compelled to deny the charge of having set out with pre-formed notions. The change in his former opinions was brought about by a more intimate knowledge of the facts. 6 . By pre isure and excitation (Reiz) the axillary bud causes further changes in the fruit-scale, the formation of the keel and wings, while the central piece which is bounded by them. can separate iteelf from the side portions and assume the appearance of a special leaf. To Celakovsky's objection, that through the pressure of the bud axis, only a circumscribed depression, and not a long furrow would be formed, there is this reply, that such a furrow must be produced by the growth of the scale past the early developed bud, and that this furrow can become wider as the scale become broader. 7. These keels (midribs) of the fruit-scale press past the bud on both sides, and hinder the development of the first lateral bud-leaves, so that the first bud-leaf now arises upon the hinder side. This explanation, characterised by Celakovsky as a forced hypothesis, is supported by the fact that the leave could not become formed in a place where there is no room, and because on the other hand the two Iateral bud-leaves show them selves if the mid-ribs are wanting or remain feebly developed (Botan. Zeitung, December 8).

The Trachez iN Lampyride.--Heinrich Ritter v. Wielowiejski publishes in the November number of the Zeitschrift für wissenschaftliche Zonlogie a very detailed account of the light producing organs in Lampyris splendidula and L. noctiluca. His invesigations were carried on at Jena, in Prof. Oscar Hertwig's laboratory. He sums up the most important results as follows :-r. The tracheal-terminal-cells of M. Schultze, which become black under osmic acid, are by no means-as their name would imply-the terminations of the respiratory tubes; for these branch out further on into brush-like masses of much finer capillaries, which are without the chitine spiral; they are very attenuated, and, making their way in the peritoneal layer (peritonealhant), are numerously distributed to phosphorescent tissue. 2. The tracheal capillaries very rarely end abruptly (blind) in the phosphorescent crgans, but most frequently anastomose with one another, forming an irregular meshwork. 3. The capillaries do not seem to enter into the structure of the parenchyma. tous cells, but rather course along their surface, of ten irregularly winding around and enveloping these. 4. The tracheal-terminalcells are nothing more than the outer elements of the peritoneal layer at the base of the tracheal capillaries, which radiate in a brush-like fasbion from a chiline-spiral-trachea. Their peripheral processes represent the extension of the latter upon the capillaries, and this relationship is homologous with certain embryonic stages of the tracheal system. 5. The trachealterminal-cells are not the seat or point of departure of the lightdevelopment. If this appears first in their vicinity, it is only a consequence of the fact that these structures have, owing to their affinity for oxygen, stored up in themselves a supply of this gas, and give it off in greater quantity to the neighbouring tissues. 6. The light-producing function is peculiar to the parenchyma cells of the light-producing organs. It results from a slow oxidation of a substance formed by them under the control of the nervous system. 7. The ventral light-organ was found to consist of two layers, the parenchyma-cells of which are quite similar to one another in their morphological characters, but they differ from one another in the chemical nature of their contents. 8. The parenchyma-cells (is this the case with all ?) seem connected with fine nerve-endings. 9. The light-organs are the morphological equivalents of the fatty-bodies.

The Stones of Sarepta (Asiatic Russia). - The remarkable masses of stone found in the white sand of the Ergent Mountains at Sarepta have often caused people to inquire how they were formed. Some of them are found of the size of a hazel or walnut, and even larger; others are cylindrical, of the thickness of a half to one werschok ( 16 werschok $=28$ inches), and a quarter to a half arschin ( 28 inches) long; others again target-shaped are more than a half arschin long, and one to four werschok thick. All the cylindrical ones, which are often also forked and root-shaped, exhibit, when they are broken across, a brown kernel with a white spot in its centre. Their surface is rough, and resembles a number of drops heaped one upon and beside another. When Alexander v. Humboldt visited Sarepta, the then director, Zwick, showed him these stone formations, Humboldt, while declaring that they were worthless recent things, was unable to say how they arose. Zwick, on the other hand, regarded them as very old and very problematical. Göbel also, who was afterwards shown these stones by Zwick, was unable to explain how they were formed. When Auerbach, the secretary of the Moscow Natural History Society, paid Alex Becker a visit twenty-eight years ago, he was brought to the place where these stone deposits were. He looked for an explanation of the formation of these stones and the reason of each stone containing a brown kernel. He was told that the stones were formed by roots. Auerbach said that these would form hydrochloric acid by decomposition. Becker now believes that he can with certainty assert that these formations arise round the roots of several plants that contain milky juice. Tragopon ruthenicus, Scorzonera ensifolia, and Euphorbia gerardiana grow plentifully in the white sand. Their long roots are inhabited and seamed by insects, and when their surface is once lacerated, their milky juice keeps perpetually flowing, and as it is sticky, the chalkcontaining sand (the sand's colour is due only to the presence of chalk) settles firmly around the root. The root gradually dies, disappears, and there remains in its place a white, often hollow, kernel, together with the brown colour of the root-cortex. As the root is white under its cortex, the kernel also appears white, surrounded with the brown layer of the root-cortex. The round and target-shaped ones may originate from the milky juice running away into the sand, and therefore hardly any of them exhibit a brown kernel. Their guttiform surface can be ex plained by the drops of the milky juice. 'The cylindrical. forked, and root-shaped stones show clearly the form of the roots. Euphorbia gerardiana, to which these stone formations are chiefly ascribed, has very long roots, root-branches and root-fibres (Alec Becker, Bull. de la Soc. Imp. dis Natur. de Moscou, I882, No. i. p. 48 ).

\section{AMERICAN RESEARCHES ON WATER ANALYSIS}

THE chemical results as to animal in contrast with vegetable organic matter in water, support, in general, the conclusions that have been usually drawn as to the source of organic matter, based on the niore highly nitrogenous character of that from animal than that from vegetable débris. Still the necessity

${ }^{r}$ Concluded from p. 2 ra $_{3}$. 
for caution is shown; t.g. samples containing the refuse of canning tomatoes might have been erroneousiy thought contaminated with animal matter; others, containing a watery infusion of human freces, with vegetable matter, \&c.

Of the biological results under the same head, the most noteworthy is the well-marked pathological effect on rabbits of the injection of waters contaminated solely by such vegetable matter as would usually be thought harmless, e.g. peaty water. True, in the well-marked cases, the amount of organic matter present was large, but not beyond that in water sometimes used for drinking purposes. The Dismal Swamp water is an example; it has often been chosen for ship-supply, and has been spoken of as a source of supply for the city of Norfolk. On the theory (which has much in its favour) of disease caused by drinking water being due to the presence and action of living organisms, there might possibly be safety in drinking a peaty water, or water filtered through dead forest leaves, when fresh ; danger, when, after some exposure, bacteria had been developed; and safety, again, perhaps, after the growth of these had fallen off, and more or less of the available organic matter had been consumed. Ship-captains say the Disnal Swamp water, after a time, becomes remarkably good and whulesome.

As to the putrescent or non-putrescent character of organic matter in water, the chemical evidence goes to prove (in opposition to Tidy's opinion) that the proportionate consumption of oxygen from permanganate within the first hour is rather greater for those waters containing vegetable than for those containing animal matter. Dr. Smart has expressed the opinion that gradual evolution of albuminoid ammonia indicates the presence of organic matter (vegetable or animal) in a fresh or comparatively fresh condition, while rapid evolution indicates that it is putrescent. His interpretations in this respect proved to be correct in a large proportion of eases, but not always.

The biological results under this head accord, on the whole, with the general belief that putrescent organic matter is more dangerous than that in a fresh or but slowly decomposing condition.

Prof. Mallet proceeds to state some general conclusions with a view to sanitary application as to the value, separately and collectively, of the different processes of water analysis which have been under examination.

It is not possible to decide absolutely on the wholesomeness or unwholesomeness of a drinking water by the mere use of any of the processes examined for the estimation of organic matter, or its constituents. Not only must such processes be used in connection with investigation of other more general evidence, as to the source and history of a water, but this should even be deemed of secondary importance in weighing the reasons for accepting or rejecting a water not manifestly unfit for drinking on other grounds.

There are no sound grounds on which to establish such general "standards of purity" as have been proposed, looking to exact amounts of organic carbon or nitrogen, "albuminoid ammonia," oxygen of permanganate consumed, \&c., as permis. sible or not.

Chemical examination may be quite legitimately applied, first, to the detection of very gross pollution (as of a well from crushing of soil pipes), and secondly, to periodical examination of a water supply, so that suspicious changes from the ascertained normal character of the water may be promptly determined and their cause investigated. In the latter connexion there seems to be no objection to the establishment of local "standards of purity," based on thorough examination of the supply in its normal condition.

A careful determination of the nitrites and nitrates seems very important

If he had to watch a large city water supply, the author would use all the three processes; each gives information which the others do not. Where only simple means were practicable, the albuminoid ammonia and permanganate processes might be employed together; but in no case should one only of these methods be resorted to.

Practical Suggestions as to the Use in their present form of the Chemical Processes Studied.-In general, water samples should be examined with the least possible delay after collection. Besides examination of a water in its fresh condition, samples of it should be set aside in half-filled but closed glass-stoppered bottles for (say) ten or twelve days, and one of these examined every day or two, to trace changes undergone.

In the case of the combustion process, however skilful the analyst, duplicate or even triplicate concordant results should be insisted on. To avoid the presence of ammonia from coal gas, in the atmosphere about the water-bath, the bath should be heated by steam brought in a small closed pipe from a distant boiler (preferably in another room), and the waste steam and condensed water should be carried off to a safe distance.

As to the albuminoid ammonia process, it would be well to adopt the rule that the distillation be stopped when, and not before, the last measure of distillate collected contains less than a certain proportion, say I per cent., of the whole quantity of ammonia already collected. To diminish the loss of amines or other volatile forms of nitrogenous matter, a separate distillation should be made with alkaline permanganate added at once, besides the usual course of treatment prescribed by Wanklyn, and the results of the two distillations compared. The details of the evolution of ammonia should always be given.

The Tidy form of the permanganate process is rather to be recommended than that of Kubel, if but one be used. The time during which the fermanganate is allowed to act in the Tidy process should be increased to at least 12 , better to 24 hours, several determinations, on different samples set aside at the same time, being made at (say) $I, 3,6,9$, and 12 hours, to trace the progress of the oxidation.

Suggestions as to possible Improvements on the Processes examined deserving further Investigation-Combustion Process.The author proposes to evaporate the water in a closed vessel immersed in a water bath, and connected with a good (water jet) air pump, a condensing worm being provided for the aquenus vapour, the feed to be managed through a nearly capillary tube with a glass stop-cock. The evaporation would thus te effected within a moderate time at a fixed temperature much lower than the boiling point. The loss of organic matter by simple volatilisation or oxidation would be greatly reduced; much less sulphurous acid would be required; the tendency to formation of sulphuric acid would be reduced to a minimum, and absorption of ammonia from the atmosphere about the dish quite prevented. In te ting this last effect, two bulb tubes containing pure sulphuric acid might be interposed between the vacuum chamber and the pump.

For certain reasons it might be well to evaporate at first with the addition of a small excess of magnesia (as recommended by Lechartier), thus removing all ammonia, and then, the water having been brought down to a small volume, add a moderate excess only of sulphurous acid with a drop of a solution of ferrous salt (as directed by Frankland), and complete the evaporation to dryness-the whole in a jet pump vacuum, as suggested.

Further experiments as to the Williams method (copper-zinc couple) for removal of nitrates, are desirable.

From preliminary experiments, the author thinks nitrates and nitrites may be completely reduced by evaporating to a small bulk with no great excess of phosphorous or hypo-phosphorous acid, guarding against evolution of phosphuretted hydrogen by use of a low temperature, then adding magnesia in small excess, and completing the evaporation. The plan deserves to be carefully tested.

Albuminoid-ammonia Process, including Determination of free Ammonia.-To prevent (or at least largely reduce and make uniform) the loss of ammonia from imperfect condensation, the author would use a retort in a saline solution kept heated by steam (at say $102^{\circ}$ or $105^{\circ} \mathrm{C}$.), and condense in a glass worm surrounded by ice water, till the distillate should be brought to a uniform temperature not over (say) $5^{\circ} \mathrm{C}$. It might be still better to distil in a completely closed apparatus, with a fixed difference of temperature between the retort and the far end of the condensing tube, with glass stopcock to draw off the distillate in successive measured portions, and a small safety-valve near the cold end.

In determination of free ammonia, it might be well to try a closed distilling apparatus connected with a (water-jet) airpump, sn as to maintain a partial vacuum within, keeping the retort at a fixed temperature much below $100^{\circ} \mathrm{C}$, and collecting all the ammonia in a flask and one or two bulb tubes, with weak mineral acid placed between condenser and pump. There would be the disadvantage, however, that the prooress of evolution of ammonia could not be easily traced by its collection in separate successive measures of the distillate; and it would be necessary to ascertain whether the application of the Nessler test would be at all interfered with by the sodium salts formed from the acid used.

To overcome, if possible, the most serious difficulty in the 
way of correct determination of free ammonia, viz. the ready breaking up of urea (and other amides) when present, on heating with sodium carbonate, it woul 1 be well to ascertain if Schlœsing's method for determination of ammonia admits of being applied to such excessively minute amounts of it as the water analyst is concerned with.

In conduction of the albuminoid-ammonia process proper, i.e. the distillation with alkaline pe manganate, the author would keep the original volume of liquid in the retort constant, by admitting ammonia-free distilled water through a capillary tube. with a glass stop-cock. When there is so much organic matter as to reduce, wholly or greatly, the usual charge of alkaline permanganate, he would first determine at about what a rate the reagent is used up, then progressively supply its solution, so as to keep the original strength as nearly as possible unaltered.

Permanganate Process. - The principle involved in the last paragraph applies also to this process. There should be a con. stant excess of permanganate all through the process. The process should be carried on at a pretty nearly fixed temperature (say $20^{\circ} \mathrm{C}$. if the Tidy method be $\mathrm{f}$,llowed).

In conclusion, the author expresses a wish that more extended biological experiments should be made as to the effects of water variously polluted on the lower animals (other animals as well as rabbits), and that the action of water introduced into the stomach as well as hypodermically injected, should be tested. It would be well to have chemical examinations, on uniform plan, from time to time made of the water supply of the largest cities at periods when the general assent of medical men indicates unusual prevalence of, or exemption from, the classes of di ease most probably capable of origination from the organic pollution of drinking-water. The author wo 1 ld especially sugge it a combined chemical and biological inquiry as to the possible effects upon living animals of the ferment or ferments of nitrification in different stages of that process. Some minor questions connected with development of nitrites and nitrates from decomposing organic matter als 3 deserve further examination.

\section{LOCKYER'S DISSOCIATION-THEORY 1}

IN February, I880, I took occasion, on the ground of my observations to the spectrum of chemically pure hydrogen, to take objection, to Lockyer's view, that calcium, at a very high temperature, is dissociated. ${ }^{2}$ From the fact, inter alia, that of the two calcium lines, $\mathrm{H}^{\prime}$ and $\mathrm{H}^{\prime \prime}$, only the first is present in the spectra of so-called white stars photographed by Huggins, Lockyer proceeded to lay down the theory that calcium at a high temperature is decomposed into two substances, $\mathrm{X}$ and $\mathrm{Y}$, of which the first gives the line $\mathrm{H}^{\prime}$, the other the line $\mathrm{H}^{\prime \prime}$, and that in the stars referred to, only the first is met with. Against this I urged that hydrogen, besides the four known and easily visible lines, has a remarkable line of very intense photographic power, which nearly coincides with Fraunhofer's $\mathrm{H}^{\prime}$, and that one is the more warranted in regarding the supposed calcium-line observed by Huggins as a fifth hydrogen line, that the hydrogen lines in the spectra of those stars are developed in a striking manner, and also the ultra-violet star lines observed by Huggins, agree with the ultraviolet hydrogen lines photographically fixed by me. ${ }^{3}$

Lockyer, however, has not given up his idea of dissociation, but sought new proofs of it by the s ectroscopic method.

$\mathrm{He}$ calls attention to the fact, inter alia, that in the spectrum of sun-spots, certain iron-lines appear broadened, and others not; that, moreover, many of them, as $\lambda 4918$ and $\lambda 4919^{\circ} 7$ do not occur in the spectrum of protuberances, which show other iron lines, but do in the spectrum of spots; that in the latter again, the iron lines are occasionally absent, which the former contain, and he proceeds to say: "there is, accordingly, no iron in the sun, but only its constituents." 4

This argumentation Liveing and Dewar ${ }^{5}$ have already opposed, having proved that certain spectral lines of a substance, e.g. $\lambda 5210$ magnesium, and various calcium-lines, are only visible when certain foreign matters are present ; in this case hydrogen on the one hand, and iron on the other; that accordingly the

${ }^{2}$ A piper by Herr Hermann W. Vogel, read to the Berlin Academy on November 2, 1882. Communicated by the author.

2 Proc Roy Soc Communicat

3 Monatsb. der Berliner Acad. der Wiss., 1880 , p. 192.

3 Monatsb. der Berliner Acad.

5 Proc. Roy. Soc., 30, 93. Wied. Beibl., iv. 366. absence of certain iron lines in the spectra of the spots or protuberances may $n$ t be attributed to a dissociation, but to the absence of foreign matters which occasion the appearance of these lines in force.

Lockyer now takes his stand, however, on another fact, which is n t explained by Liveing and Dewar's experiments, and which certainly seems to afford a firmer basis for his theory of dissociation than the facts referred to above. He says ${ }^{1}$

"The last series of observations relates to the degree of mo. tion of vapours in the sun-spots, which it is known, is indicated by changes in the refrangibility of lines. If all lines of iron in a spot were produced by iron vapour, which moves with a velocity of $40 \mathrm{~km}$. in a second, this velocity would be indicated by a change of the refrangibility of all lines. But we find that that is not the case. We find not only different motions, which are indicated by different lines, but observe in the degree of motion the same inversions as in the breadth of the lines. This fact is easily explained, if we suppose dissociation, and $I$.know no more simple way of explaining it."

Lockyer cites as an example that in the spots of December 24, I880, and January $\mathbf{I}$ and $6, \mathbf{1} 88 \mathrm{r}$, a certain number of iron lines appeared bent, while others remained straight.

Now I believe it is possible to explain these facts on the basis of numerous observations in spectral analysis of absorption without needing to have recourse to the hypothesis of dissocia. tion.

It is known that the position of the absorption-band of a substance depends very essentially on the dispersion of the medium in which it is dissolved or incorporated. One often observes that in strongly dispersive media the absorption-bands of a substance are displaced towards the red. ${ }^{2}$ Now, the remarkable case often here occurs that certain absorption-bands are displaced with the increase of dispersion of the solvent, while others are not. Thus Hagenbach observed that, e.g., the chlorophyll bands I. III. and IV. lie more towards red in alcoholic than in etheric solution, while the band II. in both solutions shows exactly the same position. I observed similar cases with uranian protoxide salts ${ }^{3}$ and with cobalt compounds. ${ }^{4}$

Now Kundt has already called attention to the fact, that for absorption-spectra of gases the same rule holds good as for the absorption -spectra of liquid substances. He adds, indeed : "It is only questionable whether, if, e.g. hyponitrate gas be mixed with various other transparent gases, the displacements of the absorption-bands are so considerable, that they can be perceived." This doubt, however, does not affect the rule sup. posed, but merely its experimental verification. ${ }^{5}$ The supposition, then, is permissible that, in the same way as with liquids, added media also affect the position of absorption-bands in the case of gases, and that in this case, as in the other, displacements of certain bands occur, while the position of others remains unaltered.

When, therefore, in sun-spots, certain iron lines suffer a displacement, and others in the same place do not, the cause is not motion, but the admixture of a foreign, strongly dispersive gas, which acts on the displaced lines and not on the others. It follows from this, further, that curvatures of absorption lines of the sun-spots need not by any means be al ways explained as due to motion of the absorbing gases in the direction of the line of observation, but only where all lines of a matter participate in the curvature.

That bright lines of a luminous gas, also, in like circumstances, "by admixture of another non-luminous vapour, or one giving a continuous spectrum," may suffer a displacement, Kundt has already shown.

\section{UNIVERSITY AND EDUCATIONAL INTELLIGENCE}

Marcus M. Hartog, D.Sc., M.A., F.L.S., has been appointed to the Professorship of Natural History at Queen's College, Cork, vacant by the death of Prof. Leith Adams.

1 Herr Vogel quotes a translation in Naturforscher.

2 Kundt, Fubelband Pogg. Ann., p. 620

3 Vogel, "Pract. Spectralanalyse." Nördlingen bei Peck. P. 248 .

4 Monatsb. der Akad. der Wiss. of May 20, 1878 .

5 Kundt formerly doubted also the possibility of proof of an anomalous dispersion in ceeded in getting such proof in the case of sodium vapours (Wicd. Ann. Io, p. $3^{2 \mathrm{I}}$ ). 